\title{
Conceptualizing Personal and Institutional Integrity: The Comprehensive Integrity Framework
}

\author{
Hugh Breakey, Institute of Ethics, Governance and Law, Griffith University \\ Tim Cadman, Institute of Ethics, Governance and Law, Griffith University \\ Charles Sampford, Institute of Ethics, Governance and Law, Griffith University
}

\begin{abstract}
We present a conceptual and terminological system - what we term the 'Comprehensive Integrity Framework' - capable of applying to both personal and institutional integrity, and to different levels of institutions (including sub-institutions and institutional complexes). We distinguish between three sorts of integrity: consistency-integrity (whether the agent's acts accord with her claimed values); coherence-integrity (whether the agent's character and internal constitution accord with her claimed values), and; context-integrity (whether the agent's environment facilitates her living up to her claimed values). We then employ this conceptual system to explore similarities, differences and overlaps between personal and institutional integrity, drawing in particular on moral philosophic work on personal integrity (on the one hand) and 'integrity systems' and public administration approaches to institutional integrity (on the other).
\end{abstract}

Keywords

Integrity; Personal integrity; Institutional integrity; Comprehensive Integrity Framework; Integrity Systems; Compartmentalization.

\section{Introduction}

What is the relationship between personal integrity-the idea of integrity applied to individual people-and institutional integrity - the notion of integrity applied to organizations and regimes? Are the two types of integrity exactly the same, or quite dissimilar? Do they follow similar or different logics? Can reflecting on each type furnish us with insights about the other? This Article aims to help answer these questions.

Specifically, we have two major purposes. The first is to provide a conceptual and terminological system - the 'Comprehensive Integrity Framework'. The Framework is intended to help us think and speak about different aspects of integrity, as that term applies to both individual persons and larger institutions. As with most such efforts of conceptual 'under-labouring', the immediate goal is to illustrate the alternative ways of conceiving the core concept, and to help theorists and practitioners avoid talking past one another. In turn, the Framework can help people think systematically about their own integrity, or that of the institutions to which they belong. As well, the Framework can be used as a tool to assist in externally appraising the integrity of a person, institution or institutional complex. It helps remind us that integrity is a complex notion, implicating actions, words, reflection, internal constitution, external pressures, and more. 
Our second purpose is to tease out some preliminary answers to several of the key questions thrown open by the Framework. With the conceptual Framework in tow, we broach such questions as: What insights about institutional integrity can we draw from the considerable philosophical work on personal integrity? Why do institutions have a more formal, public process for declaring the values and goals they endorse - and why does the law take such a close interest in institutions' failures to comply with these values? And does an institution's pursuit of its own integrity encourage (or thwart) its members' personal integrity?

The Article proceeds as follows: Section One advances the core of the Comprehensive Integrity Framework, providing basic terminology and concepts applicable to both personal integrity and institutional integrity. ${ }^{1}$ Building on this Framework, Section Two explores personal integrity in greater detail, surveying the considerable work done over the last few decades on the philosophy of personal integrity. Section Three then applies this Comprehensive Integrity Framework to institutional integrity, drawing in particular on the 'integrity systems' approach developed by Jeremy Pope and Charles Sampford and widely utilized by Transparency International. In Section Four, we turn to some of the differences between personal and institutional integrity our analysis has unearthed, and offer some reflections on the reasons underlying these differences.

Throughout we use the term 'agent' as the subject of integrity, applying it to both individuals and institutions (though we recognize a lurking danger of anthropomorphizing institutions through employing this term). Institutions can be formal or informal, including government branches, companies and corporations, community groups, charities, intergovernmental organizations, and so on. Large institutions (or 'complexes' of institutions) can contain many smaller institutions nested inside the larger entity. In all cases, however, there must be sufficient cohesion across the institution in question to make sense of speaking of it as an 'agent'.

\section{Basic terms and concepts}

Sampford was one of the first theorists to both distinguish and link individual and institutional integrity. While several different formulations were used (Preston \& Sampford, 2002b), a recent summary highlights that ethics:

...involves asking yourself hard questions about your values, giving honest and public answers, and trying to live by those answers. If you do, you have integrity in the sense that you are true to your values and true to yourself... Institutional ethics applies the same approach to institutions. It involves an institution asking hard questions about its value and values, giving honest and public answers, and living by them. Doing so for an institution is more complex than for an individual but it is both possible and necessary. The first vital questions that must be asked of any institution or organisation are: what is it for? Why should it exist? What justifies the organization to the community in which it operates, given that the community generally provides privileges? ... Asking those questions involves an institutional and collective effort under an organisation's own formal and informal 
constitutional processes (including getting acceptance from relevant outsiders - including shareholders and/or relevant regulators). An organisation has integrity if it lives by its answers. However, it does so in a different way to an individual. It cannot merely be a personal commitment but must be an institutional commitment that involves creating mechanisms which make it more likely that the organisation keeps to the values it has publicly declared and to which it is publicly committed. These mechanisms are collectively called an 'integrity system'. ${ }^{2}$

This article seeks to build on these ideas and to tease out various elements of integrity. Applied to either individuals or institutions, integrity can alert us to aspects of an agent's internal qualities (virtues and values), its external environment or its actual observable behavior. This section will introduce the array of terms the Comprehensive Integrity Framework employs to capture the different notions of integrity focusing on each of these objects. Our approach in this section will be to largely stipulate terms-later sections will help illuminate the reasons behind these definitional decisions.

\section{'Claimed values'}

The fundamental organizing concept for studying integrity is the agent's claimed values (the answers given to those 'hard questions'). As we will see in later sections, the nature, content, provenance and modes of realization of these claimed values differs for individuals versus institutions. Compared to individuals, institutions profess their values in more formal and public ways, and these values play a role in socially justifying the institution's existence and activities. But in both the individual and institutional cases, the basic concept and logic remains the same: the individual or institutional agent endorses certain virtues, norms, pursuits or goals as central to their identity, and displays these values through their public interactions - in what they proclaim, advertise, argue for, and so on. The claimed values are what the agent professes to stand for (Calhoun, 1995). Integrity then hinges on the extent to which the individual holds true to those values.

Of course, claiming values does not itself entail integrity. If the agent does not claim to stand for any particular values or goals, or the values the agent claims to stand for are inconsistent, incoherent or evanescent, then that agent cannot possess integrity. ${ }^{3}$ Equally though, possessing claimed values does not demonstrate integrity. The values are only claimed, and may not be truly endorsed by the agent. Even if they are endorsed, they may not be reflected in the way an individual agent acts or an institutional agent operates.

\section{Comprehensive integrity}

As we define it, an agent enjoys comprehensive integrity if its activities, its deeply-held ethos and internal constitution, and its external relations all accord with its claimed values. This definition draws on the inter-related ideas that integrity involves acting in accord with one's publicly asserted values ('consistency') as well as being integrated ('coherent'). It also includes attention to the way the agent fits with its external environment ('context'). Comprehensive integrity requires coherence-integrity, context-integrity and consistencyintegrity on an ongoing basis. 
The remainder of this section explains these three key terms of consistency-integrity, coherence-integrity and context-integrity.

Consistency-integrity

If an agent's activities ${ }^{4}$ are consistent with its claimed values, then it displays what we term consistency-integrity. In this reckoning, the agent's activities are not considered piecemeal. For an agent to display consistency-integrity none of its activities, assessed over a considerable period of time, can clash with its claimed values. (For example, an agent cannot claim consistency-integrity if she avoids corruption or conflicts of interests 'most of the time'.)

Consistency-integrity focuses purely on the agent's activities, and compares these activities to the agent's claimed values. So understood, consistency-integrity does not demand that the activities are in fact motivated by the agent's claimed values. The activities must accord with the claimed values, but need not be performed on the basis of those values. For this reason we could say that an agent with consistency-integrity acts with or displays integrity, but we could not (on the basis of consistency-integrity alone) assert that the agent possesses integrity. For possessing integrity requires more than mere compliance; it requires having certain sorts of internal features such as intentions, dispositions and character. These make up the domain 'coherence-integrity'.

\section{Coherence-integrity}

While consistency-integrity appraises the agent's acts, coherence-integrity refers to the agent's enduring qualities. For an individual, coherence-integrity applies to her character: does she have the type of stable values, virtues, emotional dispositions, will-power, reflective practices, decision-making processes and public persona that integrate ('cohere') together in order to promote her living up to the values she claims?

Similarly, for an institution coherence-integrity applies to the institution's internal qualities in particular, its members' deeply-held values (insofar as those values impact upon the members' behavior within the institution), and the nature of the institution's internal organizational arrangements. These 'internal organizational arrangements' answer such questions as: How does the institution make its decisions? How does it seek to ensure that the actions of its members further the values it claims? To what extent does it recognize the temptations and dilemmas faced by its members in performing their duties? What structures does it have for explaining its mission and what it means for its members and their actions? How does it police and encourage compliance with institutional decisions? Do the institution's policies for transparency, accountability and critical feedback promote its ability to live up to its claimed values? If the institution's internal organizational arrangements on decision-making, accountability, compliance and suchlike drive its successful implementation of its claimed values, then the institution will possess a high coherence-integrity. 
We saw above that consistency-integrity compares an agent's actions with its claimed values. Over a period of time, what does the agent $d o$ ? In contradistinction, coherenceintegrity compares an agent's internal constitution with its claimed values. Rather than looking at activities, it looks at internal qualities and processes. It asks: What is the agent?

An agent might display consistency-integrity without possessing coherence-integrity. This could occur if the agent just-so-happens, as a result of external constraints or good fortune, to consistently comply with its claimed values, with little input from its own internal qualities. Less commonly, an agent could have reasonable coherence-integrity but still fail consistency-integrity, if in an extraordinary situation, perhaps under great pressure or with an unfortunate concatenation of unlucky events, an otherwise reliable agent fails to live up to its claimed values.

If the agent is internally constituted so as to consistently live up to its claimed values (i.e. constituted so as to display consistency-integrity), then it has coherence-integrity and we can say that the agent possesses integrity.

\section{Context-integrity}

Context-integrity refers to the agent's surrounding environment and all the elements in the environment that impact upon the agent living up to its claimed values. These elements include other organizations, cultural norms, (economic, social and security) pressures, opportunities and temptations, and so on. Two contextual factors prove especially relevant. The agent's legal context is made up by the overarching (domestic and perhaps international) laws and regulations governing the agent. And what we will call the agent's organizational-context is constituted by the institutions or institutional-complexes of which the agent makes up one part. When one agent (as an individual or 'sub-institution') forms part of a larger institution, we will say it is 'nested' in that larger entity.

We have just said context-integrity refers to environmental elements impacting on whether the agent lives up to their claimed values. But as the foregoing discussion of consistencyintegrity and coherence-integrity implies, this phrase 'lives up to' is ambiguous. Do we mean that the agent's actions conform to what is required by their claimed values (with consistency-integrity), or that the agent's actions are performed on the basis of their claimed values (with coherence-integrity)?

Context-integrity can refer to the external environment's impacts on both types of integrity. Some elements in an agent's environment will cultivate changes to the agent itself, by encouraging certain virtues and decision-making methods, requiring agents to constitute themselves in various ways, or challenging them to re-think their values and how they achieve them. Other external elements can constrain an agent's behavior irrespective of its internal qualities, through incentives to good behavior (including reputational benefits and promotion), through coercive punishment triggered by non-compliance with specific rules, through channelling behavior (making it easy to the right thing, hard to do the wrong thing), or limiting the agent's capacity to engage in certain acts. As a loose rule of thumb, and as we 
will see in more detail below, studies of context-integrity in the personal realm tend to target the former (coherence-integrity) question of promoting internal changes to the person's character. Context-integrity in the institutional realm, in contradistinction, hones in on the latter (consistency-integrity) issue of policing external compliance over the institution's actions.

The distinction between these two ways context can influence character versus behavior can be seen through considering what would happen if overnight the context changed, and the external mechanism was no longer producing its previous effect. If the mechanism only produced compliance through coercive deterrence, then the agent will be left with no reason to comply when the coercion disappears. But if the mechanism produced genuine internal change to the agent, then the agent will still comply with the relevant values even if the mechanism disappears. Of course, this difference is not a bright-line distinction; an agent in an environment where its corrupt actions are immediately sanctioned may well come to invest its thoughts and energies in non-corrupt directions, and these inclinations may ultimately transform the agent's values and decision-making processes (an insight historically driving the development of the separation of powers (Breakey, 2014a, p. 38)).

Simplifying, there are three different ways a contextual factor, or the overall context, might relate to the agent's integrity (either coherence- or consistency-integrity). The context might, a) facilitate and empower the agent's integrity; b) thwart and retard the agent's integrity; or c) align with the agent's integrity. In this last case, the surrounding environment does not directly promote the agent's integrity, but at least accords with it. Since the values of different peoples and diverse organizations can easily clash in at least some circumstances, aligning the external context with the integrity of a given agent can be an important task. For example, efforts to align the profession of medicine (as an external context) to the integrity of devoutly religious doctors opposed to abortion, constitute a difficult and controversial endeavour (Magelssen, 2012). The challenge here is to develop rules that allow the professional duties to align with personal integrity.

\section{Personal integrity}

Over recent decades philosophical literature on integrity has developed rich resources for understanding the nature of personal integrity (especially, as we will see, its coherenceintegrity). The Comprehensive Integrity Framework aims to incorporate many of the key insights uncovered by this literature. Recall that the Framework takes its fundamental formulation of integrity as an agent asking itself hard questions about its values, giving honest and public answers, and trying to live by those answers (Sampford, 2010). Other influential accounts of personal integrity argue for similar formulations. Tim Dare (2010, p. 123), for example, holds that, '...what matters for integrity is that the agent has engaged in appropriate critical reflection upon the projects upon which they purport to ground their identity and that they are prepared to act upon that reflection'. 
On this footing, integrity combines a number of distinct elements. It fundamentally involves reflection about how to develop and cohere one's values (asking 'hard questions about values'), the sincerity to publicly profess what one stands for ('giving honest and public answers'), and the willpower to ensure the results of one's reflections are realized in one's character and actions ('living by those answers'). By incorporating these four key elements of personal integrity-reflection; values-coherence; willpower and sincerity-the Comprehensive Integrity Framework can in an eclectic spirit incorporate many of the insights of prior theorists. As we will see below, the Framework also makes indirect room for a fifth element: morality.

Why is such eclecticism attractive? Why should we opt for a version of integrity incorporating these many disparate elements, rather than one reducing personal integrity to a single elemental core? First, each distinct theory furnishes evidence for the existence of its particular element. If integrity had nothing to do with reflectiveness, for example, then it would have been almost impossible to for any theorist to craft a theory that defined integrity's essence in its reflectiveness. Second, as Martin Benjamin (1990, p. 47) observes, we can get an idea of what integrity positively requires by considering what it negatively rules out - that is, by considering the types of behaviors and characters that paradigmatically fail to possess integrity. As we will see, each element explains different failures of integrity. As none of the elements can be straightforwardly collapsed into the others, this favors an inclusive approach.

\section{Consistency-integrity for individuals}

The distinction noted above between 'acting with' integrity (consistency-integrity) and 'possessing the virtue of integrity' (coherence-integrity) applies to both individuals and institutions (Dudzinski, 2004). That said, the philosophical literature on personal integrity focuses on the person's internal qualities of mind and character, and so on coherenceintegrity. The mere fact of compliance, unless it is driven by the person's actual values and internal dispositions, can seem almost irrelevant to appraising personal integrity. This judgment drives W. H. Hindman's oft-quoted quip that, 'Integrity is doing the right thing when no one is looking'.

\section{Coherence-integrity for individuals}

As noted above, the rich literature on personal integrity focuses on internal character traits-the subject matter of coherence-integrity. In this sub-section we detail the five core aspects of a person's coherence-integrity found in this literature: values-coherence, reflection, willpower, sincerity and morality. For expository ease, we will use as an example the character of 'Ingrid', who possesses integrity.

\section{Values-coherence}

Perhaps the most obvious element of coherence-integrity involves holding 'integrated' values. Almost all accounts of integrity involve at least some measure of values-coherence, sometimes combined with one of the remaining four elements. This idea of 'values- 
coherence' can be cashed out in several ways. Values-coherence can be conceived as Ingrid integrating all of her preferences together so they press in a unified direction, or (in a more sophisticated variant) possessing integrated first- and second-order preferences, meaning that Ingrid's ordinary preferences accord with her preferences about what preferences she would like to have (Frankfurt, 1971). This idea reflects integrity as 'integration'.

Alternatively, values-coherence can refer to Ingrid's most important commitments and 'ground projects', conceived as commitments she endorses or identifies with (Williams, 1973). This idea captures integrity as the pursuit of what is 'integral' to Ingrid.

Plausibly, both the integration and integral pictures alert us to key parts of what Ingrid reflects upon and epitomizes as she coheres her values (Cox, La Caze, \& Levine, 2009; Dare, 2010). This values-coherence element follows pleasingly from the etymological root of integrity as 'unity' or 'completeness'. Ingrid has brought into harmony her key values; she has a clear, reliable identity and character. Complete consistency is not required, nor inflexibility, but Ingrid's values possess sufficient coherence to give direction to her life, and to allow her to take her values seriously, being committed to them wholeheartedly. Because Ingrid has values-coherence, she is not inconsistent, torn, self-loathing, self-alienated or capricious.

\section{Willpower}

By 'willpower' we refer to all of the emotional dispositions, habits of thought and qualities of character that together serve to ensure that Ingrid puts her values into action. These qualities ensure that Ingrid's values determine the decisions she makes, and that she follows through on those decisions by implementing them in her actions. Ingrid is not swayed from pursuing her values on the basis of temptations, distractions or fears. Through Ingrid's strong willpower, she thus displays the virtues (the emotional dispositions) of patience, decisiveness, assertiveness, diligence, courage, grit, dedication and conscientiousness.

Though theorists often subsume willpower into values-coherence, this capacity remains distinct (Benjamin, 1990, p. 48; Reginster, 1997, p. 294). 'Willpower' does not refer to the content or coherence of Ingrid's preferences, but instead to her psychological characterspecifically her disposition to feel certain emotions in certain situations, and how she responds when in the grip of those emotions. On this footing, integrity incorporates qualities of character and psychology, and essentially opposes the failures of diffidence and akrasia.

\section{Reflection}

As a person of integrity, Ingrid's values must be her own, actively and deliberately claimed by her. This requires that Ingrid has reflected on her commitments. She knows her values and that those values fit with her beliefs-and she takes some care that those beliefs are accurate. The values Ingrid endorses are not arbitrary but chosen on the basis of reasons; her values cohere at least partly because Ingrid has used her reflection to bring them into accord. 
Ingrid's reflectiveness does not demand searching philosophical interrogation, nor rigorous logical coherence. But it does require that Ingrid's reflective attention to her values includes at least some basic epistemic virtues that serve to ensure that no-one could say that she was in the grip of self-deception, or that she was shallow, wanton, manipulated, brainwashed or simply conformist. Equally, she is not merely addicted, irrationally fixated or obsessed, or monomaniacal. Ingrid beats her own path, and not that of others, and one of the things that makes it her path is that she has reflected on and endorsed her commitments. On this basis many commentators place reflectiveness at the core of personal integrity (Calhoun, 1995; Cox et al., 2009; Edgar \& Pattison, 2011; Reginster, 1997; Scherkoske, 2010).

\section{Sincerity}

Ingrid stands for her values. Those who meet her know what she stands for. Her public persona reflects her actually-held values. Ingrid is honest and faithful, not just reliable but trustworthy (Graham, 2001, p. 246). People may disagree with aspects of Ingrid's values, but they know they can trust her implicitly and rely upon her to predictably behave on the basis of her known commitments. If Ingrid decides she must break a law, she will openly take responsibility for what she has done. Indeed, in a paradigm of integrity, she may announce her attentions to 'conscientiously object' to the law ahead of time.

Theorists locating integrity's essence in sincerity locate the paradigm integrity failures in being hypocritical and two-faced (Calhoun, 1995; Luban, 2003). Because roles and positions allow for abuse if the role-holder is not sincere, corruptness and abuses of power present as symptoms of hypocrisy, and so as signature failures of integrity (Huberts, 2014). The integrity here lies in the accord between word and deed, between the public persona and the internal commitment. This element explains why honesty remains at the centre of what is 'measured' in integrity tests (Audi \& Murphy, 2006, p. 7).

\section{Morality}

Setting aside the specific virtue of sincerity, controversy surrounds the relationship between integrity and morality.

Importantly, nothing in the notion of integrity defined here demands specific moral content for Ingrid's values. So conceived, integrity is thus a process value rather than a substantive value. $^{6}$ In this way integrity resembles the traditional or 'thin' concept of the rule of law, which does not directly impact upon the content of the law, but oversees the processes by which it is applied and implemented (and thus constitutes an indirect restraint on the types of laws likely to be promulgated). Similarly, the process that integrity demands can carry significant consequences for the resulting values, even if it does not determine them. As Dare (2010, pp. 117-118) argues, when an ordinary person works to cohere their values, their common-sense moral sensitivities will be one part of the overall web of values that the person aims to cohere together, meaning that the process of attaining integrity will encourage the holding of (and having the courage to act upon) decent moral values. As well, 
the reflectiveness noted above, requiring consideration of the reasons for holding one's convictions, makes thoughtless embrace of evils less likely (Kerwin, 2012). To these points about values-coherence and reflectiveness we can add that the element of sincerity further restrains the types of values that the person of integrity will develop and cherish. Only in rare cases is a person with violently anti-social convictions in a position to sincerely stand for them in word and deed. These three constraints (values-coherence, reflection and sincerity) may not categorically rule out Ingrid holding evil values, ${ }^{7}$ but it limits the likelihood of such a result. This allows our definition's eclecticism to capture many of the points raised in connection to the element of morality. In particular, several general intuitions about the relationship between integrity and morality bear mention, even if for our conceptual purposes we resist taking them as constitutive elements.

First, Ingrid has a personal moral stance; she possesses moral commitments, reasoning and sensibility and she takes all of these seriously. This does not tell us anything about the content of Ingrid's moral life: only that she has a moral life.

Second, as just observed, the constraints of values-coherence and sincerity strongly influence the type of moral convictions a person of integrity is likely to hold. This helps explain why, while people routinely apply the term to those they disagree with on moral or political issues (Cox, La Caze, \& Levine, 1999, p. 520), it is almost never spontaneously applied to truly evil characters like Hitler.

Third, some commentators note the perplexing fact that, despite its seeming ethical desirability, a host of 'moral dangers' seem to follow from the values-coherence implied by integrity. These potential dangers include egoism, extremism, intolerance, fanaticism, moral blindness and more (Benjamin, 1990; Edgar \& Pattison, 2011; Luban, 2003; Scherkoske, 2010). A hint of these worries lurks in Nietzsche's extolling of the integrity of his 'noble man':

The noble type of man experiences itself as determining values; it does not need approval; it judges, 'what is harmful to me is harmful in itself'; it knows itself to be that which first accords honor to things; it is value-creating. (Nietzsche, 1989, p. [260])

While Nietzsche exalts in the glory integrity can infuse, he equally expresses the hubris that seems to lie within it. Despite these dangers, we do not usually apply the term to ideologues and extremists. One way or another (the precise mechanism is disputed (Calhoun, 1995; Cox et al., 2009; Scherkoske, 2010)), the intuitive application of integrity manages to skirt the serious moral dangers of taking one's own commitments to extreme levels - what Scherkoske (2012, p. 185) terms 'vicious steadfastness'. Again, our stance here, of taking personal integrity to involve the four elements of values-coherence, reflectiveness, sincerity and willpower provides the beginnings of an answer. The requirement of integrating one's values (values-coherence), of subjecting them to a level of open and critical review (reflectiveness) and of being completely public about those values and their implications to 
one's community (sincerity) serve to make it extremely unlikely - though perhaps not impossible - that Ingrid exhibits brutal extremism.

Theorists locating integrity's essence in morality see integrity essentially opposed to being unprincipled, amoral, evil or tyrannical (Dudzinski, 2004; Graham, 2001).

\section{Summation}

As this overview illustrates, the most common understanding of integrity applied to individuals refers, as coherence-integrity, to the agent's persisting internal qualities. This coherence-integrity in turn is made up of four key elements (values-coherence, will-power, reflectiveness and sincerity) and carries consequences for the subject's substantive ethical position (a fifth element of morality). As we stressed, all these key elements are captured by the core idea that personal integrity involves Ingrid asking hard questions about her values, giving honest and public answers, and living by those answers.

\section{Context-integrity for individuals}

As well as exploring the substance of personal integrity (as coherence-integrity), theorists from a wide array of disciplinary perspectives have wrestled with the ways in which an individual's environment might erode her integrity (the question of context-integrity). Ingrid's social, political, organizational and economic milieu carries strong consequences for her internalization and harmonization of her claimed values, and on the internal qualities that contribute to her acting on those values.

Unlike the situation with institutional integrity (as we will later explore), studies of the impact of context on personal integrity do not tend to focus on compliance mechanisms like coercive external oversight (e.g. police enforcement of legal duties). That is, theorists are not interested in how external context works to enforce compliance - in our terms, how context-integrity helps drive a person's consistency-integrity. Rather, philosophers studying personal integrity focus on how the external environment, including the general culture but especially the organizational context, can help or hinder a member's capacity to develop and hold her own integrity - in our terms, how context-integrity impacts upon a person's coherence-integrity. (We will later (in §4.B) reflect on possible explanations for why institutional integrity focuses on consistency-integrity and compliance, while personal integrity hones in on coherence-question and character.)

This section develops the existing insights on how context-integrity, especially that provided by Ingrid's organizational context, can threaten Ingrid's coherence-integrity. That is, we outline the ways that institutions can encourage integrity failures such as personal distress, fragmentation, compartmentalization and rationalization. Our discussion here sets the groundwork for our later consideration (in §4.E) of a key question that arises from reflection on the Comprehensive Integrity Framework's application to both individuals and institutions, namely, does institutional integrity undermine or promote personal integrity? 
At the outset, note that the context-integrity of a member of a particular institution differs conceptually from that institution's coherence-integrity. In other words, the way that Ingrid's institutional environment promotes her integrity conceptually differs from the way that the institution internally promotes its own integrity. By way of example, suppose Ingrid is a practicing doctor, and belongs to the relevant Medical Association. Ingrid's contextintegrity describes how well her entire environment-including the professional association-contributes to her upholding and acting upon her claimed values. The coherence-integrity of Ingrid's professional association refers to how well its internal arrangements and member's values (including Ingrid's values) support the association living up to its claimed values.

With that distinction in mind, let us examine the ways that Ingrid's organizational context can impact upon her integrity. The literature provides us with a wealth of perspectives on the ways that institutions can work to undercut personal integrity, including from psychological and philosophical analysis of concrete case studies (Gioia, 1992), professional histories (Luban, 2003), major legal cases (Kerwin, 2012), fictional explorations (Breakey, 2014b), qualitative social science (Kelly, 1998) and more (Maclntyre, 1999; Rozuel, 2011). These studies alert us to different institutional pressures and the different types of personal fragmentation that can result from these.

Unfortunately for the integrity prospects for organization-members, it turns out that institutions can drive several distinct types of fragmentations. We distinguish four major categories, with several important sub-categories.

\section{Compartmentalization}

In the case of compartmentalization, the organization-member unthinkingly adopts the prevailing standards of his institutional role. (We will use the pronoun 'his' in this section to distinguish the fragmented person from Ingrid, who we will return to when we discuss 'Reflective Role-Endorsement' below.) The compartmentalizer does not ever step back from the institutional standards to evaluate them from a different point of view, either from his own life-perspective, or from the value-systems inherent in the other roles that he plays.

Compartmentalization rears its head in two ways, leading to two sub-categories.

Mild compartmentalization occurs when the organization-member has (for various reasons) failed to fully apprehend that his own values, especially his moral values, need to interrupt or otherwise impact on the institutional role he is following. Dennis Gioia (1992) describes a very personal example of mild compartmentalization in exploring his own role in Pinto Fires scandal. In charge of product recalls at Ford, Gioia explains how his job was made manageable by following 'scripts': cognitive processes that mapped existing knowledge onto a template for understanding and response. Unfortunately, his company's prevailing scripts failed to recognize ethically salient features of the Ford Pinto case - namely the small car's capacity to erupt into an all-consuming fire when impacted from behind. Gioia's personal 
values should have alerted him to this concern, but the significance of the scripts in making his job manageable proved a powerful impediment to him doing so. ${ }^{8}$

Total compartmentalization occurs when the organization-member is so engrained in following role-based scripts that they can scarcely fathom how their values in one role could impact upon their values in another. This extreme case emerges in Hannah Arendt's reflections on the Nazi 'desk-murderer' Adolph Eichmann (Kerwin, 2012), and in Alasdair Maclntyre's (1999) exploration of his imagined character ' $J$ ' (who resembles Eichmann). In the case of mild compartmentalization, an agent like Gioia is able (when confronted with the reality of his actions) to 'snap out of it', and recognize that his values should have interrupted his script-following. But a character like Eichmann is incapable of such a realization. Compartmentalization so pervades his character that he can scarcely apprehend how he could criticize his role from an outside standpoint. There is no (mental or social) space available to him whereby such a critique could be made (Maclntyre, 1999). He is 'unthinking', as Arendt said of Eichmann (Kerwin, 2012).

\section{Rationalization}

Rationalization differs from compartmentalization inasmuch as the person adopting specific roles, and adhering to prevailing scripts, has not done so in an unthinking manner. To the contrary, the rationalizer has put at least some thought - and perhaps quite a lot of thought - into explaining why they adopt the particular role they do. While the mild compartmentalizer might be mortified at realizing what he has been a part of, the rationalizer is fully aware that his actions can be evaluated from a standpoint outside his specific role, and he has a story to tell about how that evaluation justifies his role. The rationalizer cares about his integrity - he actively perceives and publicly acknowledges the importance of some level of overall coherence across his values and actions.

The problem is that the rationalizer does not care enough about his integrity. The rationalizer's justifications for his role-based actions do not withstand any genuine rational scrutiny. The values he holds outside the institutional role really should impact upon his institutional behavior; they should overthrow the feeble rationalization he offers.

Explorations of professional ethics show how such rationalization can occur. In the context of the legal profession, David Luban (2003) describes how social psychological processes (such as cognitive dissonance) can gull the lawyer into too-easily rationalizing away their immoral practices and eroding their initial idealism. In the context of nursing, Kelly (1998) recounts how noble client-focused ethics can be usurped by an insular in-group loyalty, rationalized by its adherents through a perceived need to survive and prosper as part of the team. ('Us-against-them' narratives often pervade stories of integrity failures (Gioia, 1992), promoting loyalty to the organization or group above other personally held values.)

\section{Single-minded workaholic}

The single-minded workaholic has placed his work-role as the centerpiece of his life, and made everything else subservient to it. The values used in his work role are the values that 
he takes as definitive of his very person. For the workaholic, there is no perceived gap between his professional ethos and his everyday values - and to the extent gaps do arise, it is the everyday ethos that must give way.

What prevents the single-minded workaholic from having integrity? Cécile Rozuel draws on the work of Jung, and also of Goffman, in showing the inherent fragility and imbalance of a person who has taken his role's values to be his true core (in Jung's terms, who has taken his 'persona' to be his 'ego'). More broadly, as we define him here, the single-minded workaholic fails to have integrity because the way he goes about the ruthless purging of his 'life' values is unsustainable. Life, and events outside his work, must still go on. He must eventually deal with life-issues such as partners, family, children, bereavement, loneliness, friends, religion, health and the wider society, and the institutional values purpose-built for his role may prove hopeless for navigating such realms. The workaholic ostensibly denies the significance of these wider concerns. But unless he is truly a monomaniac, ${ }^{9}$ life will inevitably intrude on his working existence. When it does, his deeply-held but unrecognized values rear their heads and level their demands at him, unearthing inconsistencies that were always present. In Breakey's (2014b, pp. 72-73) exploration of role ethics in the television series The Wire, the character of Jimmy McNulty exemplifies such a workaholic: McNulty is totally dedicated to his police-work and its values and goods, to the point where his life falls apart. Eventually McNulty realizes his wrenching position. 'The things that make me good at this job', he laments, 'make me wrong for everything else'. In the series' final seasons McNulty retreats from being a detective to the lower pressures, and happier existence, of a uniformed cop walking his beat.

\section{The morally torn}

Perhaps the saddest ramification of institutional processes on personal integrity comes in the form of the morally torn. Such a person, like the rationalizer, is aware of a significant gap between their ordinary values and their institutional role. Unlike the rationalizer however, the morally torn has too much integrity to sweep the issue under the carpet. But he is unwilling to leave the institution itself - perhaps because of the personal costs of doing so, or perhaps because he knows that things will be worse in the institution if he does not remain within it. Yet he does not have the power to change the institution's practices, and his personal involvement in activities he disagrees with. This chasm between his actions and values leads him to 'moral distress', as Kelly describes in the context of the nursing profession (Kelly, 1998). The morally torn person does not have integrity, and awareness of this very fact emotionally torments him. (Such a person is, however, a candidate for having integrity in the future. Perhaps he will need to change his occupation or at least his institution, or perhaps with time and experience he will acquire the power and support necessary to reform it. But his felt anguish at failing to have integrity - a failure that currently leaves him morally torn - may ultimately lead him to achieve true integrity.) 
The distinctions between these four groups are important. The mild compartmentalizer does not notice the clash with his other values. The total compartmentalizer cannot even conceive of a clash with his other values. The rationalizer fails to treat seriously the acknowledged clash with his other values, while the single-minded workaholic has distorted all his other values in a forlorn attempt to align them with his role. The morally torn worker keenly apprehends the clash between his role and his values, but cannot or will not change either.

While these types of fragmentation differ conceptually, a single person can shift between them. For example, upon realizing he has been guilty of mild-compartmentalization, a roleholder might for a time attempt rationalization. But his own reflections, or public challenges, might force him to give up the rationalization, collapsing into being morally torn. Over time, he may assuage his moral distress by becoming a single-minded workaholic.

What drives these different types of fragmentation? All institutions can potentially pose a threat to a person's integrity, treating them as mere cogs in a larger machine. But the literature unearths several signature pressures that drive the above fragmentations. These 'usual suspects' include:

- Institutional roles that suppress autonomous decision-making (Dolovich, 2010) or emotional responses (Gioia, 1992);

- Institutional roles heavily reliant on scripts to process and respond to information (Gioia, 1992);

- Institutional roles where the neophyte is thrown 'out of his depth', removing the capacity for self-confidence in his own values and evaluations. (Kelly, 1998);

- Institutional roles and perceptions encouraging an us-and-them mentality (Gioia, 1992; Kelly, 1998);

- Institutional roles that involve lying, exaggerating, dissembling or advocating for positions one does not believe (Cox et al., 2009; Luban, 2003);

- The prevalence of clumsy metrics of quantified performance evaluation (Breakey, 2014b; Kelly, 1998);

- Resource and time constraints, including being continually forced in new directions for reasons of expedience (Breakey, 2014b; Gioia, 1992; Kelly, 1998);

- Institutional roles where small breaches are unpoliced, and can grow surreptitiously into larger violations (Luban, 2003);

- Institutional roles that don't allow space for raising concerns about practices, or that don't possess institutional space for integrity-preserving mechanisms such as (where appropriate) internal whistleblowing or conscientious objection mechanisms (Maclntyre, 1999; Magelssen, 2012);

- Societies with little space for reflection and activity in one realm to be linked to the values of another institution (and perhaps little overlap in the personnel of each realm) (MacIntyre, 1999); 
- Modern societies of pluralism and dynamism, or where tensions exist between an institution and its wider community, making a consistent narrative difficult to hold (Benjamin, 1990, pp. 68-71; Breakey, 2014b).

\section{Reflective Role-Endorsement}

Of course, it is not all bad news. Simply because the values and practices a person employs in their organizational-role differ from the ones they use in other parts of their life does not necessarily mean the person fails to possess integrity. To the contrary, role-holders often perform vital tasks that cannot be done well without adopting distinct ways of behaving, valuing, feeling and thinking. Because these tasks can be important, either to an individual or to her society, Ingrid can have very good reason to take up the role necessary to fulfil her institutional task. In this case she resembles the 'rationalizer', who puts forward reasons explaining and justifying the clear gap between his ordinary values and his role-identity. The single but profound difference, of course, is that in Ingrid's case the defense is a genuine, reasonable one, capable of being reflectively endorsed by Ingrid - and usually upheld and acknowledged by the wider society. Her defense is also bound to be a nuanced one, allowing Ingrid to take recourse to her own values where necessary, and to mitigate the role-identity in various principled ways. ${ }^{10}$

\section{Contingency}

What activities Ingrid performs, and what effects they have, emerge from both her coherence-integrity (who she is) and her context-integrity (what her environment is). But as well as these stable, ongoing factors, other events can occur that create new and unforeseen dynamics or pressures. In a given case, whether or not these events impact upon Ingrid's pursuit of her claimed values is a matter of 'contingency'. Contingency constitutes 'sudden shocks', unprepared-for exceptions, and surprise events.

As we noted above, contingency (in the form of an unfortunate concatenation of unlucky events or extraordinary pressures) may create a situation where, despite an agent having solid coherence-integrity, she ultimate fails to perform with consistency-integrity. ${ }^{11}$

Together, the three causal elements of coherence-integrity, context-integrity and contingency determine Ingrid's activities and the extent to which they accord with her claimed values. As a result, in any given case, coherence-integrity, context-integrity and contingency together determine consistency-integrity. (See Figure One: Personal Integrity Conceptual Map.)

We do not include contingency only for the sake of completeness in the causal factors determining Ingrid's actions. Contingency matters to discussions of integrity. The greater Ingrid's coherence-integrity, and the healthier her context-integrity, the greater the resilience she will display to contingency's slings and arrows, and their capacity to impact upon Ingrid living up to her claimed values.

\section{[Figure 1: Personal Integrity Conceptual Map]}




\section{Institutional integrity}

While much philosophical attention has surrounded personal integrity over the last few decades, institutional integrity remains comparatively less studied. Despite this, ordinary speakers routinely apply the term 'integrity' to institutions, companies and organizations. 'In fact,' as Audi and Murphy $(2006$, p. 5) describe, 'integrity has appeared in 20 percent of company mission statements and is the most frequently mentioned value in corporate values statements.'

The application of the term 'integrity' to institutions seems appropriate to the extent we can view institutions as agents; collectively, institutions issue statements, make decisions, comply with norms and undertake actions. But the term 'integrity' can also apply in a descriptive sense to inanimate objects, and its employment in this respect also reflects some of what we might expect from the idea of institutional integrity. Dudzinski (2004, p. 300) explains: 'In the descriptive sense, the bridge has integrity because its purpose, design, and function are in harmony. ... A bridge would lack integrity if it was not reliable as a bridge and did not meet our expectations of bridges.' Daniel Wueste (2005) draws a similar link with health. Just as the idea of institutional integrity parallels in many respects the normative concept of personal integrity, so too it captures many of the features of these descriptive meanings of the term.

In what follows we apply the Comprehensive Integrity Framework's terminology and conceptual analysis to institutional integrity, aiming to capture the thrust of both ordinary invocations of institutional integrity and recent theorising upon it.

\section{'Claimed values' for institutions: The 'Public Institutional Justification' (PIJ)}

What in the context of personal integrity are the relatively informal 'claimed values' becomes in the context of institutional integrity the more explicit and formal notion of the 'Public Institutional Justification' (PIJ). Usually including an account of the raison d'être of the institution (what it is 'for'), the PIJ is what the institution's members and representatives use to justify the institution and to show the public it deserves their support or at least tolerance (Preston \& Sampford, 2002a, pp. 47-48). The PIJ justifies the risk the community takes in the creation of another institution whose powers could be abused and used against the community (Sampford, 2010). When the institution's actions, powers or existence are called into question, institutional members and representatives aim to re-establish its credentials by asserting its PIJ. While the PIJ is wholly chosen by the institutionmembers/representatives, it nevertheless reflects wider community values, as these are the audience for the justification. Like an individual's claimed values, the PIJ can be a mere fiction, little more than a slick public relations document. If so, it fails to genuinely justify the institution, and to contain 'honest and public answers'. To attain institutional integrity, an organization must not merely present a PIJ, but must live by it.

Many accounts of institutional integrity draw on this key organizing idea of the publicly asserted or acknowledged purpose of the institution (Preston \& Sampford, 2002a, pp. 37- 
38; Wueste, 2005, pp. 15-22). As Buchanan and Keohane (2006, p. 428) observe, offering public justifications is itself a core part of an institution's achievement of integrity and transparency. Equally, the 'front page' test (Huberts, 2014, p. 46) is a well-known device that encourages both reflection on, and compliance with, the institution's PIJ.

\section{Consistency-integrity for institutions}

Paralleling consistency-integrity for individuals, if an institution's activities are consistent with its PIJ, then it has consistency-integrity and 'acts with' integrity. For institutions, consistency-integrity is arguably the key organizing concept: it is natural to ask whether the institution's acts accord with its words-and often much of social import hangs on the answer to this question. We can see this in talk of integrity systems (including external features like a free and vigorous press that act as a watchdog), integrity violations, and integrity measures (such as Crime and Misconduct Commissions). None of these notions focuses its attention on coherence-integrity and a concern for internal qualities like values and virtues. Instead, the focus lies with consistency-integrity-on whether or not the institution's actions accord with its PIJ. For example, an integrity breach or integrity violation does not occur when an institution possesses a vulnerable internal organizational arrangement. Rather, it occurs when the vulnerability manifests in an actual breach of a rule, or in a poor outcome. This is why, coming from a public administration background, Huberts (2014, p. 7) can assert (against the philosophers' focus on the internal intentions, character and values central to personal integrity) that, 'chiefly, however, the integrity concept concerns behaviour...'

\section{Coherence-integrity for institutions}

For institutions, coherence-integrity comprises two factors: (a) coherence on members' values (including moral values): the institution's members hold personal values that contribute to the institution pursuing its PIJ. (This does not envisage full consensus but merely that individual members conceive of their role morality as being congruent with the institutional values. ${ }^{12}$ ) Coherence integrity also includes, (b) coherence of internal organisational arrangements. 'Internal organisational arrangements' consist of the processes governing how the institution makes its decision, the structures it uses for policing and encouraging compliance with those decisions, its policies on transparency, accountability and critical feedback, and any other arrangements that impact upon it living up to its PIJ. When working well, these internal organizational arrangements help create the PIJ and ensure that the institution pursues its PIJ.

In the ideal institution, these two factors of members' values and internal organisational arrangements ensure that the PIJ remains workable and acceptable to all those institutionmembers bound by the PIJ. An institution whose values and internal organisational arrangements cohere with its PIJ possesses high coherence-integrity, as all its pieces fit together and push in the same broad direction. Wueste $(2005$, p. 27) knits together values, purpose (PIJ) and coherence-integrity thus: 'in order to achieve the purpose, one has to 
comply with the normative constraints intrinsic to the enterprise, which is essentially the task of maintaining its integrity.' Ideally, the internal organizational arrangements of the institution reliably produce compliance with the PIJ even if the agents are not themselves saints. Alternatively, the internal arrangements may encourage the institution-members' formation of appropriate values and integrity. In the less ideal circumstance, an institution loses coherence-integrity if, 'its practices or procedures predictably undermine the pursuit of the very goals in terms of which it justifies its existence' (Buchanan \& Keohane, 2006, p. 423).

In last section's discussion of personal integrity, we noted five elements constituting coherence-integrity. We can draw on this philosophical work to illuminate aspects of institutional integrity, as each of these elements have analogues in the institutional context.

- Values-coherence: In assessing an institution's value-coherence, we ask: does the institution's stated PIJ reflect, or at least prove congruent with, the actual values held by its members, authorities and representatives? Does the institution actually possess a PIJ, or does its public relations department merely 'talk the talk' without the institution possessing a genuinely shared self-understanding of its values? Does its members' professional integrity promote the larger institutional integrity? We saw earlier that for personal integrity the idea of values-coherence refers to the existence and coherence of key values within an individual person. For institutions, values-coherence becomes the existence and coherence of 'member's values' across the institution.

- Willpower: Speaking of institutional 'willpower' is overly anthropomorphic, but nevertheless alerts us to a key issue. Merely possessing integrated values, without mechanisms to translate them into action, was insufficient to ensure personal integrity. For persons, this required willpower and virtuous emotions and dispositions. For institutions, this requires the 'internal organizational arrangements' mentioned above that ensure the institution makes its decisions based on its PIJ, and for the resulting decisions to be duly enacted.

- Reflection: Reflection plays a role both in the development of the PIJ and institution's values, and in the extent to which the institution's decisions and action correspond with its PIJ. Institutions possess reflection when they have decision-making and feedback processes that allow institution-members to inject values-based reasons into discussion and policymaking, and when the institution ensures that members understand the reasons for its decisions, rather than merely acquiescing in them.

- Sincerity: Sincerity requires the institution's actual behavior tracks its public persona (its PIJ). Transparency and accountability (both internal and external) are key parts of the relevant internal organizational arrangements here (Buchanan \& Keohane, 2006, p. 431). But the processes for decision-making are at least as important; for example, does the institution routinely apply a 'front page' test to its internal decision-making? 
- Morality: The three moral facets of personal coherence-integrity implied: i) possessing moral commitments; ii) the commitments not being morally beyond the pale; and iii) avoiding the moral dangers of egoism and extremism. Refracted onto institutions, the first facet is included in the idea of the PIJ: as a justification for the institution, the PIJ necessarily requires that moral concerns shape the institution's claimed values.

Similarly, the PIJ's public nature will usually institutions with integrity capture the second element of moral decency, because public scrutiny will not tolerate morally repugnant institutional behavior. The third concern looms large for institutions too: moral danger threatens when the institutional interest becomes so strong that it swamps all other social and moral factors. This might occur when the institution, or its mission, are seen as sacred and demanding of unquestioned loyalty (such as a church, a charity, or a state during war), when the institution's members believe that their wellbeing inextricably depends on the institution's flourishing and survival, and when members perceive the institution to be under attack. In all these cases, the interests of various individuals may attach so strongly to the institution as to overwhelm its pursuit of its PIJ-loyalty to the institution's survival and strength trump loyalty to the purposes the institution claims to pursue (in our terms, the risk is that members-values distort and swamp the larger coherence-integrity).

\section{Context-integrity for institutions}

Perhaps even more than the case with individual people, whether an institution will in fact behave in accord with its PIJ (i.e. whether it will have consistency-integrity) does not hinge primarily on its coherence-integrity. The behavior of the institution will be substantially influenced by its external environment, including the institution's relationships to other organizations. The institution possesses 'context-integrity' if its external environment tends to facilitate the institution acting in accordance with its PIJ.

The importance of surrounding institutions for promoting consistency-integrity is a feature of many studies of institutional integrity (Buchanan \& Keohane, 2006, p. 432). Indeed, in recent literature on integrity systems and accountability, focus has shifted from the existence of discrete anticorruption institutions to the overall network of inter-relations between institutions. The network's primary goal is the promotion of integrity; combating its opposite (corruption) remains a secondary and derivative, though necessary, element (Sampford, Smith, \& Brown, 2005). This attention to structuring external relations to achieve institutional integrity resurrects insights dating all the way back to ideas on the separation of powers, balance of powers, and checks and balances, arising in the work of Machiavelli, Locke, Montesquieu and other early modern political theorists (Breakey, 2014a; Rahe, 2011; Sullivan, 2006; Vile, 1998; Zuckert, 2012).

\section{Nested institutions}

Context-integrity includes 'nested' relationships with larger institutions (or networks of institutions like the 'justice system'). An institution can be one part of a larger institutional 
complex that has its own PIJ and undertakes its own activities and tasks on a larger scale. In this case we will call the institution one 'sub-institution' nested within a larger 'regime'. An essential-even legally determined-part of the sub-institution's PIJ may be that the subinstitution plays an official part in the regime's pursuit of the regime's PIJ. In this case the sub-institution is a 'formal' part of the regime. When the sub-institution's PIJ accords closely with the regime's PIJ, the sub-institution's consistency-integrity will contribute to the regime's coherence- and consistency-integrity. Equally, a regime's coherence-integrity will facilitate the institution's context-integrity.

Alternatively, the sub-institution may link less officially with the larger regime; its PIJ may only accord indirectly with the regime's PIJ. In such cases it is only an 'informal' part of the regime. This may mean that while an informal sub-institution's activities tend to accord with the regime's PIJ, at some times its priorities will diverge, and its consistency-integrity (its actions in accord with its own PIJ) will run counter to the regime's consistency-integrity.

In either case the sub-institution may enjoy different sorts of relations with its larger regime and the other parts of that regime. As part of institutional design, the institution might relate antagonistically to other elements of the same regime, as occurs for example in some incarnations of the separation of powers (Rahe, 2011). Alternatively, the institution may have a supportive or 'associational' relation to other institutions surrounding it in the regime, with each acknowledging the others' role in securing the larger objective (Little, 2000, pp. 11-12).

\section{Other relations}

An institution's context-integrity also includes reference to all the other bodies, individuals, norms, social factors, economic situations, standards, laws and institutional complexes, that impact upon the institution's pursuit of its PIJ. Some of these other bodies may promote, and others undermine, and others go to lengths to accord with, the institution's activities in compliance with its PIJ.

Integrity system

Together the internal qualities of the institution, and the qualities of its external environment, make up the institution's 'integrity system' (Preston \& Sampford, 2002a). The integrity system thus combines the institution's coherence-integrity and context-integrity. It encompasses all the 'business-as-usual' operations and factors in the agent's world that impact on its performance.

\section{Contingency}

Contingency works in the same way as it does for individuals-namely, as including those unprepared for, sudden events that impact upon the agent's actions. Because it lies outside business-as-usual, such events are not part of the institution's 'integrity system' - but the more robust the integrity system, the more resilient the institution's integrity will be to these external shocks. 


\section{Scope and the Comprehensive Integrity Framework}

The 'institution' chosen as the object of study can be larger or smaller. The conceptual system remains the same when scaled up or down. At the smaller scale (e.g. shifting from a specific organization to one of its sub-committees), relations or arrangements that previously featured under the organization's 'coherence-integrity' would then be considered as part of the sub-committee's external relations (and so a part of the 'organizational context' of its context-integrity). Likewise, when scaled up (e.g. from the organization to the larger regime complex of which it forms one part) relations and arrangements that were external context would now be captured within the internal organizational arrangements of coherence-integrity. In the proposed conceptual and terminological system, each different grouping can be focused upon as the institution under analysis (with the proviso that each institution must possess a PIJ).

\section{[Figure 2: Institutional integrity map]}

\section{Differences and reflections}

We have seen that the Comprehensive Integrity Framework maps personal and institutional integrity using the same terms and concepts. In so doing, the Framework has unearthed several revealing differences between, and inter-relations amongst, the two applications of integrity.

Five of these issues warrant reflection.

\section{A: Individuals have 'claimed values', but institutions need a 'PIJ'}

An institution's PIJ differs from an individual person's claimed values in several ways. Compared to claimed values, the PIJ has to be more formal, and often appears in a concrete form - a charter or creed or mission statement, or at least a slick public relations manifesto. As well, the PIJ is usually more publicly accessible than an individual's claimed values. Despite her personal integrity, Ingrid can be quite a private person, and it may only be when she is asked or expected to engage in some particular practice, or when someone voices an opinion on a particular topic central to her values, where her committed stance becomes clear. An institution's PIJ, contrariwise, is usually available for all to see. As one last point of distinction, the PIJ serves a particular purpose that personal claimed values need not-the PIJ aims to justify the institution's existence and activities. It is not just an uncompromising statement of the institution's purposes, but an apologia-a defence of its operations.

Why do these differences exist between an individual's 'claimed values' and the institution's PIJ? We offer three reasons. First, because institutions bring together several people, the process whereby shared values are debated, created, settled, changed, communicated and encouraged in new members needs to be a matter of public record. For organizations, the processes of reflection, decision and memorizing cannot happen in the same internal way possible in the case of personal integrity. 
Second, institution's purposes must be far more interwoven with the law. To be properly registered and functional, certain associations require charters, churches perform specific sorts of tasks, and companies take on certain (e.g. fiduciary) responsibilities. These mean that various parts of an institution's PIJ may be reflected in, or required to be made explicit through, laws and regulations. Indeed, in many cases the PIJ and the codes and constitutions that apply and contextualize it need to be signed off by minister, formally resolved at an $A G M$, and so on.

Finally, PIJs need to give prominence to the issue of justification because institutions, far more than individual people, require legitimacy to exist and function - not least to justify the risk that the community takes that the institution's concentration of power, people and resources might be used against that community rather than for the values that constitute its PIJ. Institutions benefit greatly by being seen as legitimate and purposeful by their members - a voluntary organization that cannot justify itself to its own members is clearly under threat. But many organizations also require various types of legal and social privileges, or the support and patronage of parts of the local population, to survive and prosper. Individual persons do not require this level of justification; they have human rights preventing their liquidation-and rightly so. As well as not having any intrinsic moral worth, institutions possess more raw strength than a given individual acting alone. By 'raw strength' we refer to the sheer power and resources possessed by an institution that empower it to survive, expand, resist, compel, resource, reward, disrupt, threaten and influence (Breakey, 2014a, p. 32). Institutions draw together substantial economic, material and other resources, and if this power is employed for antisocial purposes it can constitute a far greater danger than that posed by an individual person. For this reason, policing institution's activities constitutes a particularly urgent social need.

For all these reasons, then, it should not surprise us that institutions come to possess a slightly different notion of claimed values-one more public and concrete, and more attuned to the specific business of validation: the Public Institutional Justification.

\section{B: Why isn't coherence-integrity a focus for institutions?}

The previous sections showed that studies of personal integrity honed in on the agent's internal qualities (coherence-integrity), while research into institutional integrity took the agent's actual behavior (consistency-integrity) as the key concern. What is the reason for this difference of priority between the two applications of the same idea? Specifically, why do we hold institutions to account-even legally to account-for their actions in pursuit of their publicly stated purposes, but do not similarly hold persons responsible to the same degree? Why does personal integrity reside in the realm of supererogatory aspiration, while institutional integrity is a matter of law, regulation, constitutionalism and professionalism?

A large part of the answer, we submit, is that the institution's purpose structures its very existence. Legal entitlements, regulations and social expectations take their shape from the institution's purpose. Society and law respond differently to community organizations, 
churches, multinational corporations, small businesses and public services. Each of these institutions requires certain sorts of legal privileges and entitlements to function. So too, depending upon the type of resources the institution commands, each poses specific sorts of threats to individuals and communities. Social and legal practices thus need to respond to institutions very much based upon the institution's professed purpose.

For individual people, it is quite otherwise. The same law and the same rights, more or less, cover people with very different values and aspirations; Ingrid might totally revise her values without the law needing to accommodate such a shift in any way. The devout spiritualist, the enterprising entrepreneur, the dedicated artist, the social reformer-all of these can possess largely the same legal entitlements and obligations. This means that society does not require legal machinery or strong social sanctions to ensure that Ingrid acts in accord with her claimed values. Whether she does so or not is a matter for her own conscience, and for our social appraisal of her character.

Additionally, institutions almost by definition act on behalf of collectives. Corporations act on behalf of their shareholders; public administrators on behalf of taxpayers and citizens; and so on. The collective hands over its powers and resources to the institution on the condition that these investments are to be used in a particular way, or for a particular purpose. Any action that breaches that purpose thereby wrongs the collective's members. For individual people, again, the situation differs. In the usual case, if Ingrid betrays her own values, the primary person who loses is Ingrid, and all her prior investments in those values. Others will not have the same cause for complaint; Ingrid is not abusing their investments. The powers and resources she is redirecting are her own. True, there are situations where Ingrid's self-betrayal will also harm others, perhaps her nearest and dearest, or those that have trusted her to live up to her values and supported her in doing so. But the general point remains that when an institution egregiously fails to live up to its PIJ, individual people's material investments are almost always misused. If Ingrid fails to live up to her specific claimed values, we can make no automatic presumption of an abuse of power.

For these two reasons, then, it makes sense for our concern with institutional integrity to focus on what the institution does. For an individual person outside of an institutional setting, on the other hand, our concern need not be legalistic or regulative, but a more social judgment about who that person is.

\section{C: Claimed values and the PIJ differ from 'members values' for institutions}

The values and principles a person upholds and internalizes just are their claimed values. For individuals that possess integrity, we can read off the person's claimed values directly from their held values. The 'values-coherence' at the top-left-hand corner of Figure 1 thus constitute the 'claimed values' that form Ingrid's personal standard of integrity.

For institutions the relationship between the members' values and the PIJ proves less straightforward. 'Members' values' can relate to any norm, ideal or principle, held by any member of the institution, that ultimately helps the institution live up to its PIJ. This need 
not mean the norm itself forms part of the PIJ. Institution members can have values that promote the PIJ by comporting the member appropriately to various parts of the institution or environment around them. A member may have values that guide her engagement with any of the parts of her governing integrity system: with her colleagues, with the internal organizational arrangements, with the laws that regulate her, with the larger organizations to which she belongs, and with the community at large. In short, members' values may facilitate their interaction with every part of the integrity system described in Figure Two.

By way of example, consider the public service as a profession. Drawing together prior research, Huberts (2014, pp. 84-85) lists an array of diverse values found in the public administration literature, categorized in terms of public servants' relationships with different agents and organizations. Translated into the language of the Comprehensive Integrity Framework, these public sector values can ensure proper action with respect to internal organizational arrangements within the public service itself (e.g., the virtues of innovation, timeliness and productivity), with respect to the organizational context provided by the elected politicians (e.g., the virtues of loyalty and responsiveness) and oversight regimes (e.g., openness and accountability), with respect to their legal environment (e.g., respect for rule of law, legality, equal treatment), and finally with respect to the external context of the stakeholder communities (e.g., citizen involvement, user orientation, professionalism). None of these values, important as they are, would actually feature as part of the profession's PIJ-but all of these values in various ways support the public sector in meeting its PIJ. Needless to say, the public sector also possesses values that relate directly to its PIJ, in the form of the sector's commitments to contribute to society (e.g., virtues such as promoting the common good, social cohesion, regime dignity, and so on.). In this case we can see that the members' values of the public sector include values that directly parallel the sector's overall PIJ, as well as a multitude of operative norms that instrumentally aid the institution in securing the realization of that PIJ.

In sum, all the members' values (on the top left hand corner of Figure 2), if they are to aid coherence-integrity, must support the pursuit of the PIJ. Sometimes, this will mean the member's values simply are part of the PIJ (as we saw with the public sector's values of the common good). Other times the member's values differ from the PIJ, but nevertheless work in support of it (such as with openness and respect for the rule of law). Again, this contrasts with the personal case, where Ingrid's claimed values will always form part of her valuescoherence. Because Ingrid genuinely holds those values, they count as part of her claimed values.

D: Corruption and abuse of power strikes at the heart of both personal and institutional integrity

When we think of integrity failures, or the need for integrity measures, or when the term 'integrity' shouts from the news headlines, the subject of discussion almost always surrounds corruption or the abuse of power (Huberts, 2014, p. 8). The conceptual system provided above explains why this is so: namely, these types of behavior represent striking 
violations of both personal and institutional integrity. They constitute a perform storm of integrity failure.

We have seen that personal integrity involves sincerity. When our person with integrity (Ingrid) deliberately and voluntarily joins an institution with clear and well-known practices, norms and values (and thus with a definite PIJ), Ingrid inculcates a social expectation that she will conform to those norms. Issuing from this social expectation, Ingrid's sincerity demands that she upholds those qualities - or publicly and explicitly refuses to do so, such as through conscientious objection. Ingrid's embrace of the institutional norms then becomes part of her own claimed values, and her professional integrity incorporates into her own integrity. Needless to say, rules against corruption and abuse of power will inevitably feature in the institution's norms-if an institution's PIJ explicitly endorsed and publicized its policies of abusing power, then they would no longer be abuses of power in the ordinary sense. As such, if Ingrid were to violate those norms, she would be betraying not only her own integrity and the professional integrity that forms part of it, but also undermining her institution's integrity. Little wonder, then, that abuse of one's institutional role constitutes the canonical example of a failure of integrity.

\section{E. Tensions between institutional and personal integrity}

We noted earlier that an institution's coherence-integrity was not conceptually the same as the context-integrity of an institution-member (qua individual person, like Ingrid). We also surveyed ways that an institution might erode a member's integrity, resulting in their becoming a victim of compartmentalization or rationalization, or a single-minded workaholic, or morally torn.

Having provided an account of the nature of institutional integrity, our final question arises: What is the relationship between institutional and personal integrity? The values and practices of each individual member impact upon the institution's coherence-integrity, and the values and practices of the institution impact upon each individual member's contextintegrity. This opens an intriguing question: do institutions with high (coherence) integrity inevitably promote their members' integrity? Or-to the contrary-does a high institutional integrity actually threaten the personal integrity of its members?

Three possible outcomes spring to mind. First, it may be that institutional integrity intrinsically clashes with personal integrity. After all, we might suppose that a fragmented institution, with little integrity, might be more beneficial to its members' integrity, precisely because its fragmentation and lack of control allowed more space for member's personal autonomy. More specifically, the institution might threaten its members' integrity if it can only achieve integrity by treating its members as little more than cogs in a larger mechanism, or if the institution's task required its members to suddenly shift in their convictions (undermining their values-coherence) or to systematically lie to others (undermining their sincerity). 
A second possibility is that there is no tension whatsoever, and that an institution with integrity necessarily promotes and accords with the integrity of each of its members.

In fact, it is unlikely that either of these two absolute answers will prove correct. Because institutions possess very different PIJs, they can pursue very different instantiations of institutional integrity, and persons pursuing very different instantiations of personal integrity can wind up working for these institutions. Whether the two pursuits fit together will be a contingent, contextual question. Thus, a more likely (third) possibility emerges that certain specific types of institutions will (as they pursue their own institutional integrity) pose special challenges to certain specific individuals (as they pursue their own personal integrity).

While there are thus no hard and fast answers to the relationship between institutional and personal integrity, we can still make some general claims about the likely effects of institutional integrity on personal integrity. Recall that an institution with integrity has asked hard questions of its values, given honest and public answers, and does its best to live by those answers. Recall too that asking those hard questions will (ideally) mean involving the institutional members in the discussion and development of its PIJ.

The institution's development and commitment to the PIJ can facilitate the personal integrity of its members in several ways. First, the public nature of the PIJ means that institution-members, performing their required activities, can do so in a sincere fashion. Clients, stake-holders and the community are not being misled by the institution or its members.

Second, the public nature of the PIJ helps prospective members make an informed decision about whether they want to join the institution. Prospective members will be less likely to harbour an idealized or unrealistic notion of what the institution stands for. This does not mean that only prospective members whose values 'fit' the institution's PIJ will join. An entryist might join an organization precisely because they want to radically reform it. Others may want to take it in new directions. Still others may interpret the PIJ differently (indeed the PIJ may be subject to varied formulation at any one time and certainly over the longer term). These different interpretations of the PIJ and those who want to take it in new directions may prove vital for institutional dynamism and long term institutional development. ${ }^{13}$ While the publicity and honesty of the PIJ will thus not prevent divisions between members (and prospective members) about the PIJ's substance, such sincerity will diminish the shocks that a neophyte encounters on being exposed to the reality of practice at the coal-face (Kelly, 1998), which should in turn lessen the likelihood of 'morally torn' members.

Third, the institution's commitment to its PIJ in word and deed makes it likely that the PIJ actually does serve, to some extent at least, as a genuine justification of the institution to its community. This does not mean the PIJ, qua justification, is fully accepted by every stakeholder, but it does mean that the PIJ is more than a facile rationalization. As a result, 
an institution with integrity does not need to force its members into rationalizations. Why rationalize what you are doing when you have a sensible, public justification (the PIJ) on offer?

Equally, the fact that the PIJ is publically well-known makes compartmentalization less likely. Recall that compartmentalization occurs when the institution-member does not (or cannot) reflect upon the values internal to their work from a perspective outside that work. But the PIJ, and its process of development, amounts to exactly such a perspective. An institution that sincerely holds its PIJ fully acknowledges that its internal workings and norms should be subject to critical inquiry from other perspectives, and it develops its PIJ precisely to mediate between the institution's goals and the community's priorities. In involving its members in the development and awareness of the institutional PIJ, an institution with integrity thus greatly reduces the prospects of compartmentalization.

As a general rule, then, we can conclude that institutions with integrity remove many of the pressures towards institution-members' compartmentalization and rationalization - two of the signature threats to members' personal integrity. Turing to the 'morally torn' integrityfailure, the public nature of the PIJ removes some of the threats to personal integrity here, but it is doubtful that institutional integrity can entirely ameliorate this possible outcome. Real-world institutions must manage under resource and time constraints, and respond to specific events and sudden priorities, and these factors may ignite tensions between individual members wanting to do their own specific jobs 'the way they should be done', and the institution's pursuit of its goals within the existing constraints (Breakey, 2014b). As well, the solution an institution develops to a particular task, as found within its PIJ and its resulting practices, may not accord with the considered ethics of every institutional member. Examples of this clash would include medical practitioners who believe abortion falls outside proper patient care (Magelssen, 2012), or lawyers (especially criminal defense lawyers) who find that the 'zealous advocate' model of professional lawyer's ethics clashes with their ordinary moral commitments (Dolovich, 2010). Institutions that provide mechanisms for conscientious objection, internal whistle-blowing and the raising of formal objections may help strike a balance between the needs of the institution and the individual in these matters.

But perhaps the largest threat to a member's personal integrity from the institution's integrity comes in the form of the 'single-minded workaholic'. To be sure, an institution with a reasonable PIJ will try to avoid setting up the type of 'us-against-them' mentality that so often serves to encourage single-mindedness. But other problems arise. Merely because an institution has reasonable, legitimate internal norms and values (justified through its PIJ) does not mean that those norms and values should permeate a member's life outside the organization. The norms might function well in allowing the institution to flourish without being good ways of managing one's personal life more generally. As well, the important and laudable work that the institution performs (in its successful pursuit of its PIJ) may encourage a member to prioritize her institutional role when she reflects on her own life 
and what she stands for. Sensitive to the importance of her institutional role, Ingrid conceives of herself foremost as a 'doctor', 'scientist' or 'humanitarian', for example. These factors can combine in tempting the institution-member to allow her institutional roleidentity to swamp her other values and commitments - to allow the persona to masquerade as the person, to the detriment of her personal integrity (Rozuel, 2011).

While these thoughts are general and preliminary in nature, they suggest that institutions possessing great integrity manage to remove some of the key threats to their member's personal integrity (compartmentalization, rationalization and some forms of moral distress), but may pose special dangers in other ways (namely, the worthwhile goals they pursue may come to be so highly valued by the members that some members begin to devalue their lives outside the institution).

\section{Conclusion}

In this paper we have developed the Comprehensive Integrity Framework-a conceptual and terminological system for thinking about integrity in both its personal and institutional forms. Wielding this system facilitated us in considering the ways that insights into personal integrity can impact on institutional integrity, and vice versa. Equally, we uncovered intriguing differences in the way integrity functions in application to persons versus institutions.

Of course, these reflections may need to be revised in the light of further argument and research. Integrity as an unified, cross-disciplinary research subject is only beginning to come of age (Huberts, 2014). But we hope that the terminology and concepts we have introduced, and their ability to clearly map across the individual-institution-regime field, provide the language in which such explorations can occur, and so will help us improve our understanding of integrity as an integrated topic of research.

\section{References}

Audi, R., \& Murphy, P. E. (2006). The many faces of integrity. Business Ethics Quarterly, 16(1), 3-21.

Benjamin, M. (1990). Splitting the Difference: Compromise and Integrity in Ethics and Politics. Kansas: University of Kansas.

Breakey, H. (2014a). Dividing to conquer: Employing the separation of powers to structure institutional inter-relations. Research in Ethical Issues in Organizations, 12, 29-58.

Breakey, H. (2014b). Wired to Fail: Virtue and dysfunction in Baltimore's narrative. Research in Ethical Issues in Organizations, 11, 51-80.

Buchanan, A., \& Keohane, R. O. (2006). The Legitimacy of Global Governance Institutions. Ethics and International Affairs, 20(4), 405-437.

Calhoun, C. (1995). Standing for something. Philosophy, 92(5), 235-260.

Cox, D., La Caze, M., \& Levine, M. (1999). Should we strive for integrity? The Journal of Value Inquiry, 33, 519-530.

Cox, D., La Caze, M., \& Levine, M. (2009). Integrity and the fragile self. Aldershot: Ashgate. 
Dare, T. (2010). Distance, Detachment, and Integrity. In T. Dare \& W. B. Wendel (Eds.), Professional Ethics and Personal Integrity (pp. 100-124). Newcastle upon Tyne: Cambridge Scholars Publishing.

Dolovich, S. (2010). Ethical Lawyering and the Possibility of Integrity. In T. Dare \& W. B. Wendel (Eds.), Professional Ethics and Personal Integrity (pp. 125-185). Newcastle upon Tyne: Cambridge Scholars Publishing.

Dudzinski, D. M. (2004). Integrity: Principled Coherence, Virtue, or Both? The Journal of Value Inquiry, 38, 299-313.

Edgar, A., \& Pattison, S. (2011). Integrity and the moral complexity of professional practice. Nursing Philosophy, 12, 94-106.

Frankfurt, H. (1971). Freedom of the Will and the Concept of a Person. Journal of Philosophy, LXVIII, 5-20.

Gioia, D. A. (1992). Pinto Fires and Personal Ethics: A Script Analysis of Missed Opportunities. Journal of Business Ethics, 11(5/6), 379-389.

Graham, J. L. (2001). Does integrity require moral goodness? Ratio, XIV, 234-251.

Huberts, L. (2014). The Integrity of Governance: What it is, what we know, what is done, and where to go. Hampshire: Palgrave Macmillan.

Kelly, B. (1998). Preserving Moral Integrity: A Follow-up Study with New Graduate Nurses. Journal of Advanced Nursing, 28(5), 1134-1145.

Kerwin, A. (2012). Beyond the banality of evil: conscience, imagination and responsibility. Journal of Management Development, 31(5), 502-514.

Little, L. (2000). Envy and Jealousy: A Study of Separation of Powers and Judicial Review. Hastings Law Journal, 47, 47-121.

Luban, D. (2003). Integrity: Its Causes and Cures. Fordham Law Review, 72(2), 279-310.

MacIntyre, A. (1999). Social Structures and their Threats to Moral Agency. Philosophy, 74, 311-329.

Magelssen, M. (2012). When should conscientious objection be accepted? Journal of Medical Ethics, 38, 18-21.

Nagel, T. (1979). Moral Luck Mortal Questions (pp. 24-38).

Nietzsche, F. (1989). Beyond good and evil: prelude to a philosophy of the future (W. Kaufmann, Trans. Vintage Books ed.). New York: Vintage Books.

OECD. (1996). Ethics in the public sector: Current issues and practices. Paris: OECD.

Pope, J. (2000). Confronting corruption: The elements of a national integrity system (TI Source Book). Berlin: Transparency International.

Preston, N., \& Sampford, C. (2002a). Institutionalising Ethics. In C. Sampford, N. Preston, \& C. Conners (Eds.), Encouraging ethics and challenging corruption (pp. 32-68). Annandale: Federation Press.

Preston, N., \& Sampford, C. (Eds.). (2002b). Encouraging ethics and challenging corruption. Annandale: Federation Press.

Rahe, P. A. (2011). Montesquieu's anti-Machiavellian Machiavellianism. History of European Ideas, 37, 128-136.

Reginster, B. (1997). Nietzsche on Ressentiment and Valuation. Philosophy and Phenomenological Research, 57(2), 281-305.

Rozuel, C. (2011). The moral threat of compartmentalization: Self, roles and responsibility. Journal of Business Ethics, 102(4), 685-697. 
Sampford, C. (2010). Adam Smith's Dinner. In I. G. MacNeil \& J. O'Brien (Eds.), The Future of Financial Regulation (pp. 23-40). Oxford: Hart.

Sampford, C., Smith, R., \& Brown, A. J. (2005). From Greek Temple to Bird's Nest: Towards A Theory of Coherence and Mutual Accountability for National Integrity Systems. Australian Journal of Public Administration, 64(2), 96-108.

Scherkoske, G. (2010). Integrity And Moral Danger Canadian Journal of Philosophy, 40(3), 335-358.

Scherkoske, G. (2012). Could integrity be an epistemic virtue? International Journal of Philosophical Studies, 20(2), 185-215.

Sullivan, V. B. (2006). Against the despotism of a republic: Montesquieu's correction of Machiavelli in the name of the security of the individual. History of Political Thought, 27(2), 263-289.

Vile, M. J. C. (1998). Constitutionalism and the Separation of Powers (2nd Edition ed.). Indianapolis: Liberty Fund.

Williams, B. (1973). Utilitarianism and Integrity. In B. Williams \& J. J. Smart (Eds.), Utilitarianism: For and Against. London: Cambridge University Press.

Wueste, D. E. (2005). We need to talk... about institutional integrity. New York: RIT Press.

Zuckert, M. (2012). On the Separation of Powers: Liberal and Progressive Constitutionalism. Social Philosophy and Policy, 29(2), 335-364.

\section{Notes}

${ }^{1}$ Some distinguish between 'integrity', 'personal integrity' and 'moral integrity', but for our purposes here we consider these terms as synonymous. That is, we use the qualifier personal to contrast with institutional. For discussion, see: Jody L. Graham, 'Does Integrity Require Moral Goodness?,' Ratio XIV (2001). Pp. 240-41.

${ }^{2}$ (Sampford, 2010, pp. 33-34). On 'integrity systems', see (Preston \& Sampford, 2002b, pp. 41, 164, 171). Sampford initially described such sets of institutions as 'ethics regimes', observing the Queensland governance reforms of the early 1990s. The idea was picked up by the OECD and renamed 'ethics infrastructures' (OECD, 1996). Jeremy Pope, the founding CEO of Transparency International coined the term 'national integrity system' (Pope, 2000).

${ }^{3}$ We set aside repugnant regimes, where public professions of what an agent stands for make it impossible to further the values articulated. Arguably, Oskar Schindler exhibited great integrity, but he could not be public about his driving values. This complication might require a new category of 'clandestine ('private'/'silent') integrity'. 
${ }^{4}$ We use this term to cover individuals and institutions. We could use 'actions' to cover the former. The institutional equivalent of personal actions involves the way that the institution's power and resources are used by its leaders and members.

${ }^{5}$ Of course, achieving values-coherence will limit the amount of genuine temptations on offer. However, aligning values does not remove the need for emotional fortitude. A person frightened of public speaking still needs courage (however much the speech aligns with her values).

${ }^{6}$ Provided we understand sincerity as a process value, rather than a substantive value. The point is that (on the idea of integrity employed here) there is no in principle constraint on the content of the values the agent of integrity endorses.

${ }^{7}$ Further restraints, inherent within the concept of integrity, capable of categorically ruling out such evils are possible, but they would extend beyond the core system we advocate here. This conceptual possibility is explored in: Hugh Breakey, 'Compromise despite conviction: Curbing integrity's moral dangers' (unpublished manuscript).

${ }^{8}$ A similar case of script-following emerged during the famous Stanford Prison Experiment, where ethical values failed to intrude on the scientists' roles and scripts - requiring an external observer to call attention to the ethical violations involved. See also Rozuel's example of 'Amy' who 'does not really perceive that she compartmentalizes' (Rozuel, 2011, p. 694).

${ }^{9}$ Of course, if such a person really was totally monomaniacal in his focus on the role, to the point where such life-issues are unlikely to ever intrude on his ambitions (he spurns family and any other social ties), then he would not be a 'single-minded workaholic' as we have defined him. His life may be narrow and pinched - but he is not fragmented, and may even have integrity (if he has reflectively endorsed and publicly professed his values).

${ }^{10}$ Rozuel's case example of 'Vincent' is an exemplar of a reflective role-endorsement. (Rozuel, 2011, pp. 694-696). Dolovich's argument for revision of the lawyer's role of 'zealous advocate' aims to 
${ }^{11}$ Thomas Nagel distinguishes several cases of 'moral luck'. One case involves external factors that shape one's own moral character (our category of context-integrity). Another type of moral luck (perhaps the paradigm case) concerns chance factors contributing to the success, failure and other consequences of one's attempted actions: 'Contingency' captures this source of moral luck (Nagel, 1979)

${ }^{12}$ The greater the accord on such values, the more the members' values will promote the PIJ. Even so, it is hardly necessary to have complete harmony even on core principles; diversity, dynamism, dispute and dialogue can be healthy and helpful qualities. Good institutional practice will lead to a dialogue about values that in turn leads to convergence of values or an awareness of difference. The most dynamic institutions are constantly reinventing themselves as members propose new values to pursue. That said, the PIJ must have enough substance and widespread endorsement at any given moment to provide an appropriate standard for appraisal.

${ }^{13}$ Consider western universities, the first of which predated the sovereign state by some 600 years and the limited liability joint stock company by 800 years and will probably outlive both. Such longevity was not attained by remaining gathering places for masters and their students. The same kind of points could be made for the Guild of Barber Surgeons, the Inns of Court and, of course, the Catholic Church which is nearly twice as old as universities. 


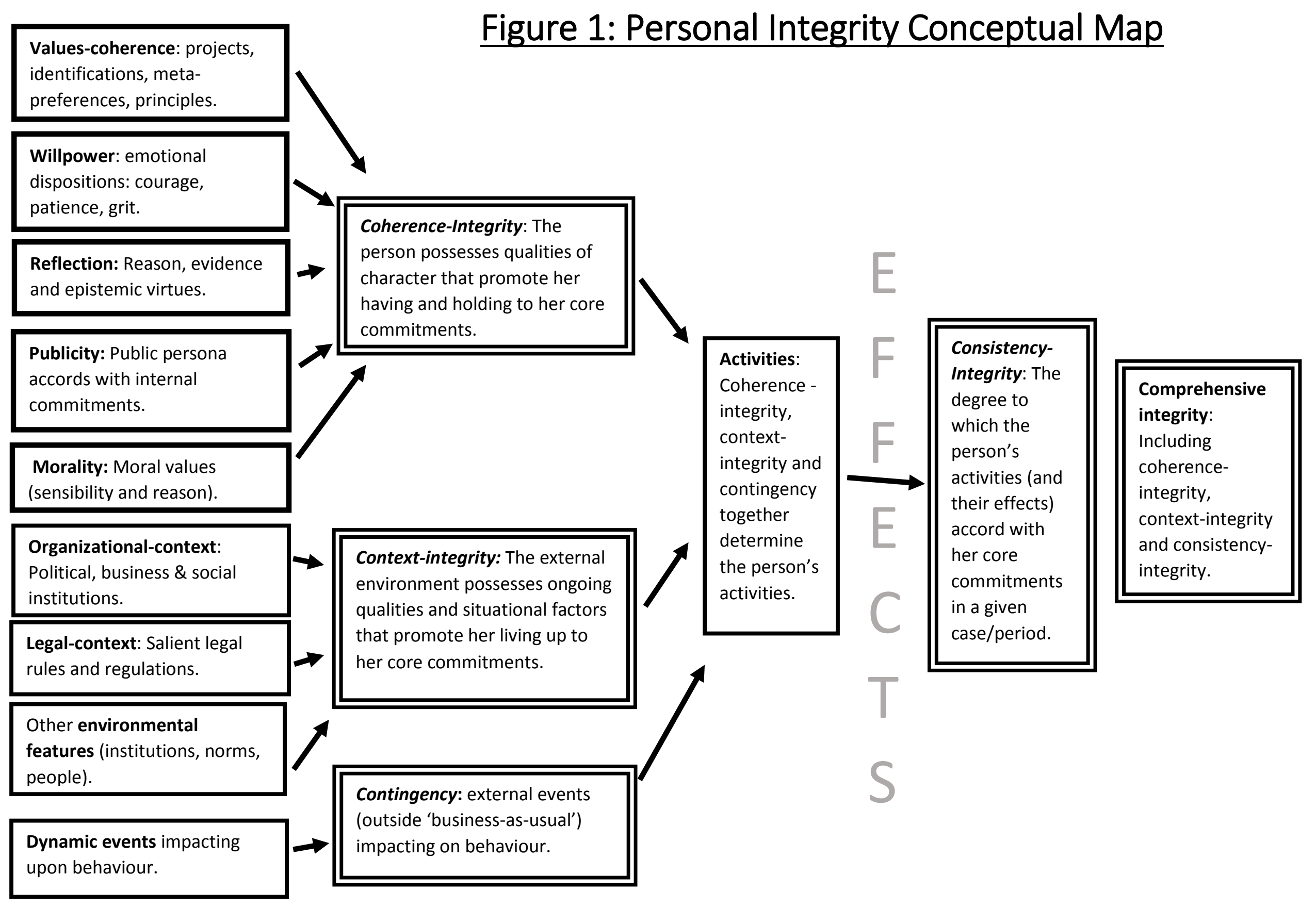




\section{Figure 2: Institutional Integrity Conceptual Map}

Member's Values that

support \& promote the PIJ.

\section{Internal organizational}

arrangements within the

institution that support the

PIJ.

regulations governing the

institution

\section{Organizational-context: All}

elements of the larger

organization to which the institution belongs.

The institution's relations

with other institutions and

actors that do not themselves

function as a larger regime.

Dynamic events impacting

upon behaviour.
The institution's 'PIJ' is its Public

Institutional Justification

\section{Coherence-Integrity: the}

institution has internal

qualities that promote its

acting in accord with its PIJ.

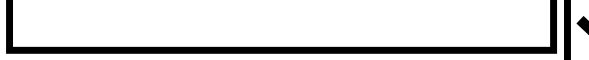

Together coherence-integrity and context-integrity make up the institution's 'integrity

system'.

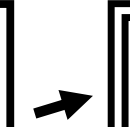

Context-integrity: the external institutional environment possesses ongoing qualities that promote the institution acting in accord with its PIJ.

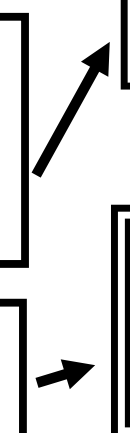

Contingency: external event

(outside 'business-as-usual')

impacting on activities.

\begin{tabular}{|l|l|}
\hline \begin{tabular}{l|l} 
Consistency- \\
Integrity: The \\
degree to
\end{tabular} \\
which the \\
institution's \\
activities (and \\
their effects) \\
accord with its \\
PIJ in a given \\
case/period. \\
Integrity: \\
coherence- \\
integrity, \\
context- \\
integrity and \\
consistency- \\
integrity. \\
\hline
\end{tabular}

